\title{
ANTHROPOMETRY OF INTERNAL ACOUSTIC MEATUS IN DRY ADULT HUMAN SKULL USING CASTING METHOD
}

\author{
Mamatha $Y^{* 1}$, Trisha.K.R ${ }^{2}$, Vishal Kumar ${ }^{3}$. \\ ${ }^{*}$ Associate Professor, Department of Anatomy, KoIMS, Madikeri, Karnataka, India. \\ ${ }^{2}$ Medical Student, KoIMS, Madikeri, Karnataka, India. \\ ${ }^{3}$ Professor, Department of Anatomy, KoIMS, Madikeri, Karnataka, India.
}

\section{ABSTRACT}

Background: The internal acoustic canal (IAC), is a bony canal within the petrous portion of the temporal bone that transmits the VII and VIII cranial nerves and labyrinth vessels. Quantitative and morphometric assessment of the internal auditory canal (IAC) are essential to establish the anatomical bases for microsurgery of the cerebellopontine angle and acoustic neuroma, which may produce bone changes and is an important intracranial pathology.

Materials and Methods: The present study was conducted on 40 adult temporal bone of adult skulls.The impression of IAM/IAC was taken using impression material Poly Vinyl Silioxane, then the measurement were taken on dry cast using digital vernier calliper. The obatined data was tabulated and analysed statistically.

Results: The mean height and width of right and left side of IAM at porous end, middle portion and fundus end was $3.56 \& 3.86 \mathrm{~mm} \& 3.48 \& 4.13 \mathrm{~mm}, 3.52 \& 3.37 \mathrm{~mm} \& 3.44 \& 3.47 \mathrm{~mm}, 3.26 \mathrm{~mm} \& 3.08 \mathrm{~mm}, 3.36$ \& $3.19 \mathrm{~mm}$ respectively. The Mean superior length \& inferior length on right side was $9.89 \& 8.43 \mathrm{~mm} \& 9.94 \& 8.59 \mathrm{~mm}$ on left side respectively. On comparing the parameters between right and left sides by using unpaired test, it was found to be statistically insignificant.

Conclusion: The present study presents a baseline data on morphometric measurements of IAM of dry adults skulls among south Indian population, also confirms that there is a differences in dimensions of IAM among different races and regions and thus emphasises need to have knowledge of normal data of different population. KEY WORDS: Temporal Bone, Variant, Meatus, Facial, Acoustic, Neuroma.

Address for Correspondence: Dr. Mamatha Y, Associate Professor, Department of Anatomy, KolMS, Madikeri, Karnataka, India. Phone No: 09448669850 E-Mail: drmamthay@gmail.com

Access this Article online

Quick Response code

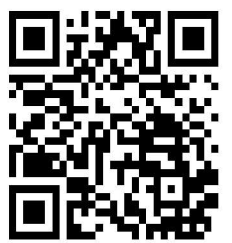

DOI: $10.16965 /$ ijar.2018.417

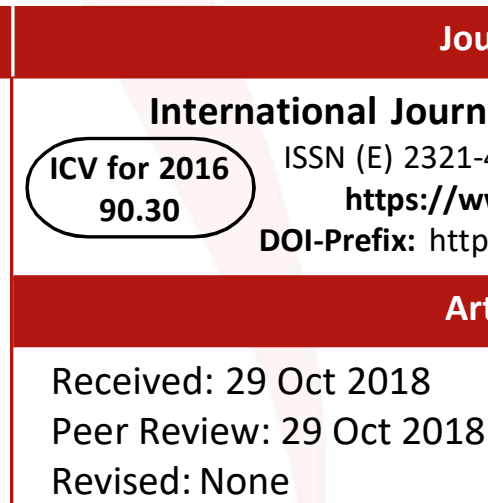

Journal Information

\section{INTRODUCTION}

The internal acoustic meatus/ Canal (IAM) is a short bony canal that lies between the posterior surface of the petrous pyramid and the bony labyrinth within the dense part of the petrous bone. The IAM opens medially to the posterior cranial fossa through the porus acousticus. The seventh and eighth cranial nerves pass through the IAM, and this canal has been clinically important as a region in which acoustic neuromas occur. Many investigators have studied the IAM on radiographs, on casts, in dissected temporal bones and in histological section and have found that the dimensions, shape, and volume of the normal adult IAM vary widely, even between two sides of the same individual, as well as among different individuals [1]. 
The internal acoustic canal (IAC), also known as the internal auditory canal or meatus (IAM), is a bony canal within the petrous portion of the temporal bone that transmits nerves and vessels from the posterior cranial fossa to the auditory and vestibular apparatus. The VII and VIII cranial nerves namely facial nerve and vestibulocochlear nerve and labyrinth vessels pass through the internal acoustic meatus. This canal has been clinically important as a region in which acoustic neuromas occur. Quantitative and morphometric assessment of the internal auditory canal (IAC) are essential to establish the anatomical bases for microsurgery of the cerebellopontine angle and acoustic neuroma, which may produce bone changes and is an important intracranial pathology. The required diameter for the neurovascular bundle running through the internal auditory canal is about $2 \mathrm{~mm}$. Therefore, a stenosis of 2 $\mathrm{mm}$ or less is regarded as significant. Possible reasons for acquired unilateral or bilateral IAC enlargement are tumors originating in the IAC such as unilateral or bilateral acoustic neuroma or, much less commonly, advanced facial neuroma [2].

Identification of the facial nerve is very essential as injury to facial nerve is a dreadful complication of ear surgery and its outcome can be most devastating to the patient as well as the surgeon. Surgical intervention in acoustic neurinomas, cholesteotomas, preservation of cochlear nerve and inner ear is an ardous task and requires dedication to prevent an unfortunate disaster. Any form of damage to the vestibule, labyrinth or cochlear can cause leakage of endolymph leading to deafness if the tumors of the cochlear nerve are dissected in a traumatic way. The location of the internal acoustic meatus and identification and location of its anatomical landmarks minimizes the chance of injury to the facial nerve and provides an insight for the surgeons to rationalize the surgical approach in an ear surgery [3].

Narrow internal auditory canal (IAC) has been well correlated with both unilateral and bilateral congenital sensorineural hearing loss (SNHL). During embryologic development, a layer of mesoderm surrounds the vestibulocochlear complex. This mesoderm layer be- comes cartilaginous and ultimately transforms into bone as IAC. Some investigators feel that the IAC develops with a smaller calibre when there is a problem with embryogenesis of the vestibulocochlear complex. Other investigators have theorised that the small caliber IAC may consequently cause dysfunction of the auditory or vestibular nerve from compressive damage. In either case, there is a clear association between the radiographic findings of a small IAC and documented congenital SHNL, both unilaterally and bilaterally. It is known that cochlear nerve (CN) hypoplasia is associated with narrow IAC, and it was also found that most patients evaluated for congenital SNHL had a qualitatively deficient CN [4].

According to Rajanigandha Vadagaonkar_et.al., 2016 of Mangalore, Internal acoustic meatus (IAM) is a chief landmark in various neurootological surgeries like removal of acoustic neuroma, temporal bone fractures and certain congenital anomalies. Understanding the anatomy of IAM is relevant during these surgeries to avoid injury to vital structures in its proximity like jugular bulb and saccus endolymphaticus. The aim of present study is to describe morphometry of internal acoustic meatus with respect to the landmarks on posteroinferior surface of temporal bone and clivus. Twenty seven disarticulated temporal bones and thirty five dry skulls were used for the study. The shape of internal acoustic meatus was noted by direct inspection, whereas the dimensions such as vertical and horizontal diameter of internal acoustic meatus and its relation to important anatomical landmarks were measured in millimeters using digital vernier caliper. Internal acoustic meatus was either elliptical or round in shape. The average length and width of internal acoustic meatus was $7.51 \mathrm{~mm}$ and 4.52 $\mathrm{mm}$. The average distance from internal acoustic meatus to superior petrosal sulcus, jugular foramen, sigmoid sulcus, and clivus was $7.15 \mathrm{~mm}, 7.77 \mathrm{~mm}, 20.60 \mathrm{~mm}$, and $24.68 \mathrm{~mm}$ respectively. The data obtained from the present study are anticipated to provide an insight for better surgical exposure of IAM and might prove to be beneficial minimizing the damage to vital structures in its proximity during any surgical procedures in this region [5]. 
Retrospective review was undertaken by A.O. El Sadik, M.H. Shaaban, 2016, for children ranged from 1 to 10 years at Egypt was of opinion that Internal auditory canal formation was dependent on the process of development and growth of the eighth cranial nerve and its subdivisions that greatly affected the completion of IAC canalization. Internal auditory canals were found normal in $66 \%$ with a mean width: $5.27 \pm \pm 0.68$, patulous in $17 \%$ with a mean width $113 \%$ more than that of the control group ( $p=0.000)$, stenotic in $13 \%$ with a mean width $73 \%$ less as compared to that of the control group $(p=0.000)$ and atretic in $4 \%$ of the experimental canals. The VCN (Vestibulocochlear Nerve) trunks were found normal with well-developed subdivisions in $77.8 \%$ of the normal canals, $98.4 \%$ of the patulous canals, and $19.2 \%$ of the stenotic canals. The VCN trunks were normal with hypoplastic subdivisions in $11.3 \%$ of the normal canals, $1.6 \%$ in the patulous canals, and $61.6 \%$ in the stenotic canals with a mean width $52 \%$ less than that of the normal trunk with developed subdivisions. Hypoplastic VCN trunks with absent subdivisions were reported in $7.3 \%$ of the normal canals, $11.1 \%$ of the stenotic canals and in $3.2 \%$ of the atretic canals. The VCN trunks were not found in $3.6 \%$ of the normal canals, in $8.1 \%$ of the stenotic canals and in $96.8 \%$ of the atretic canals [6].

Narrow internal auditory canal (IAC) has been well correlated with both unilateral and bilateral congenital sensorineural hearing loss (SNHL). During embryologic development, a layer of mesoderm surrounds the vestibulecochlear complex. This mesoderm layer becomes cartilagenous and ultimately transforms into bone as IAC. Some investigators feel that the IAC develops with a smaller calibre when there is a problem with embryogenesis of the vestibulo-cochlear complex. Other investigators have theorised that the small caliber IAC may consequently cause dysfunction of the auditory or vestibular nerves from compressive damage. In either case, there is a clear association between the radiographic findings of a small IAC and documented congenital SHNL, both unilaterally and bilaterally. It is known that cochlear nerve (CN) hypoplasia is associated with narrow IAC, and it was also found that most of the patients evaluated for congenital SNHL had a qualitatively deficient $\mathrm{CN}$ [7].

Various authors have tried to establish the normal anatomy and its variations in the same and in different individuals. The methods employed were, conventional radiography, laminography, histological sections, direct measurements of the canal or the study of casts of the canal. As various features in the development of an individual have a racial bearing, it was felt that a similar study of the normal internal auditory canal in Indians, and an assessment of its variations would be rewarding.These data may also be helpful in the presurgical evaluations of the patients undergoing surgeries involving the IAC.

\section{MATERIALS AND METHODS}

The present study was conducted on 40 adult dried temporal bones in intact adult skull obtained from the students of first year MBBS. The impression of IAM will be taken by injecting Vinyl Polysiloxane impression material (Flexceed $L B$,) into the IAM using injecting gun and allowed to dry for 5 minutes to get the Cast .Then the following parameters will be measured on the Cast using Digital Vernier Caliper (fig 1 \& fig 2).

The height of IAM at porous end bilaterally (HPR \& $\mathrm{HPL}$ )

The width of IAM at porous end bilaterally (WPR \& WPL)

The height of IAM at middle portion bilaterally (HMR\&HML)

The width of IAM at middle portion bilaterally (WMR\&WML)

The height and width of IAM at fundus end bilaterally (HFR\&HFL)

Superior length of IAM bilaterally (SLR \& SLL)

Inferior length of IAM (ILR \& ILL)

Later the cast were photographed and data obtained were tabulated and statistically analyzed using SPSS Version 20. ' $p$ " $<0.05$ was taken as significant.

\section{RESULTS}

The Table 1 shows measurement value of the height and width of IAM at porous, middle and 

METHOD.

fundus ends on left and right side. it also shows the superior and inferior length of IAM of left and right side. On comparing the parameters between right and left side by using unpaired $t$ test, it was found to be statistically insignificant. So, the dimensions of both sides were pooled together. The mean height and width of IAM at porous end was $3.56 \& 3.86 \mathrm{~mm}$ on right side \& $3.48 \& 4.13 \mathrm{~mm}$ on left side respectively. The mean height and width at middle of IAM was $3.52 \& 3.37 \mathrm{~mm}$ on right side \& $3.44 \& 3.47 \mathrm{~mm}$ on left side respectively. The mean height and width of IAM at fundus end was $3.26 \mathrm{~mm}$ \& $3.08 \mathrm{~mm}$ on the right side and on left side was $3.36 \& 3.19 \mathrm{~mm}$ respectively. The Mean superior length \& inferior length on right side was 9.89 \& 8.43mm \& $9.94 \& 8.59 \mathrm{~mm}$ respectively.

Fig. 1: Showing cast of IAM of both sides made using PVS material.

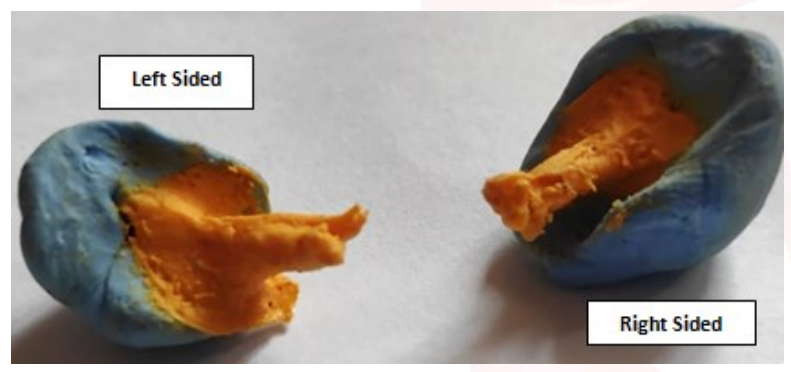

Fig. 2: Showing cast material of PVS with Vernier Calliper.

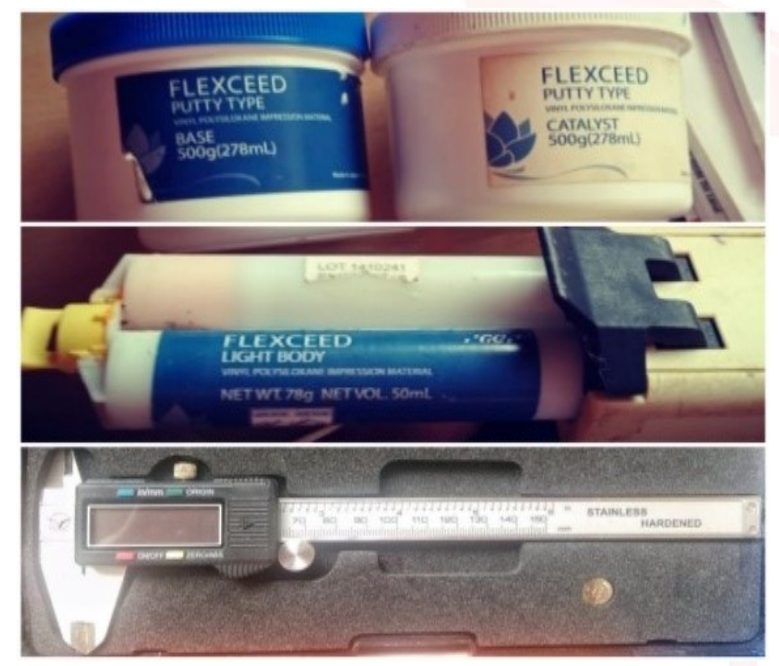

Fig. 3: A: Height at Fundus end of IAM; B: Height at Middle portion of IAM; C: Height at Porous end of IAM, D: Superior Length of IAM; E: Inferior Length of IAM.

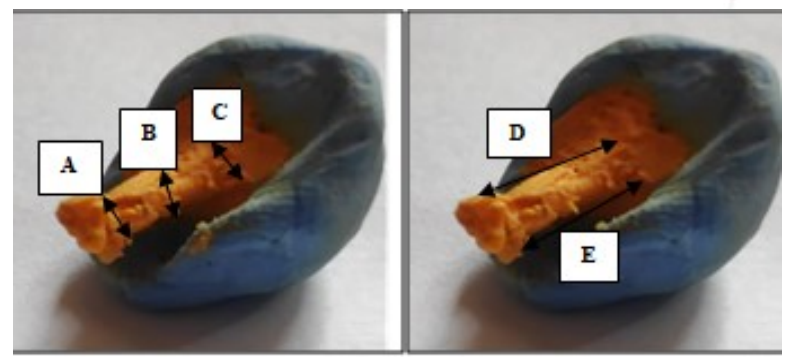

Table 1: Showing the measured values of all parameters of both sides of casts of IAM.

\begin{tabular}{|c|c|c|c|c|c|c|c|}
\hline \multirow{2}{*}{ Parameters } & \multicolumn{4}{|c|}{ RIGHT IAM. } & \multicolumn{3}{c|}{ LEFT IAM } \\
\cline { 2 - 8 } & $\begin{array}{c}\text { Range } \\
(\mathrm{mm})\end{array}$ & Mean & $\begin{array}{c}\text { Standard } \\
\text { deviation }\end{array}$ & Parameters & $\begin{array}{c}\text { Range } \\
(\mathrm{mm})\end{array}$ & Mean & $\begin{array}{c}\text { Standard } \\
\text { deviation }\end{array}$ \\
\hline RFW & $2.1-4.3$ & 3.08 & 0.45 & LFB & $2.1-4.4$ & 3.19 & 0.48 \\
\hline RFH & $2.1-4.7$ & 3.26 & 0.503 & LFH & $2.1-4.7$ & 3.36 & 0.48 \\
\hline RMW & $2.0-5.8$ & 3.37 & 0.63 & LMB & $2.2-4.8$ & 3.47 & 0.55 \\
\hline RMH & $2.5-4.9$ & 3.52 & 0.55 & LMH & $2.5-5.1$ & 3.44 & 0.6 \\
\hline RPW & $2.0-5.8$ & 3.86 & 0.7 & LPB & $2.4-5.6$ & 4.13 & 0.73 \\
\hline RPH & $2.8-4.7$ & 3.56 & 0.53 & LPH & $2.4-4.7$ & 3.48 & 0.64 \\
\hline RSL & $7.6-12.5$ & 9.89 & 1.04 & LSL & $7.0-11.7$ & 9.94 & 0.98 \\
\hline RIL & $7.2-11.7$ & 8.43 & 1.33 & LL & $7.0-10.9$ & 8.59 & 0.9 \\
\hline
\end{tabular}

RFW - Right Fundal Width, RFH - Right Fundal Height, RMW- Right Middle Portion Width, RMH- - Right Middle Portion Height, RPW- Right Porus end Width, RPH- Right Porus end Height, RSL- Right Superior Length, RIL- Rigth Inferior Length

\section{DISCUSSION}

Quantitative and morphometric assessment of the internal auditory canal (IAC) are essential to establish the anatomical bases for microsurgery of the cerebellopontine angle and acoustic neuroma, which may produce bone changes and is an important intracranial pathology. Determining gender when identifying individuals is still of the utmost importance for assessing the human body, and it is particularly interesting in the fields of forensics, anthropology and archeology. Many clinical and experimental studies have been done to analyze the anatomical and functional aspects of the IAC in human beings; however, with the advance of new diagnostic techniques in the area of otology, studies of the human temporal bone are being redone to provide better anatomical knowledge for surgeons, since there are great interindividual variability and structural variations that may occur regarding the other adjacent structures[7].

With the advent of microsurgical and radiological techniques, the surgery of acoustic neuromas is shifting from the hands of the neurosurgeon in the posterior cranial fossa, to the otologist in the internal auditory canal. Early diagnosis of acoustic neuromas is now made possible by tomography, posterior fossa contrast medium study and sophisticated audiological tests. Radiographically a difference in diameter of more than $2 \mathrm{~mm}$ between the two internal auditory canals is usually taken to be diagnostic of a tumor and yet other authors have found a distinct difference in the size of the internal auditory meati on two sides, in a normal person[8]. 
Internal auditory meatus stenosis is defined as a loss of $3 \mathrm{~mm}$ or more in the vertical diameter of the internal acoustic meatus, or even as a meatus smaller than $2 \mathrm{~mm}$. Inner ear abnormalities may occur in about $20 \%$ of the cases of patients who have sensorineural hearing loss. This loss may happen because of alterations in the VIII cranial nerve Vestibulococlear. In most cases, it happens as an isolated congenital manifestation, and other systemic abnormalities are rarely found. The major alteration happens due to a constriction caused by impaired bone growth, resulting in an abnormal internal acoustic meatus. The stenosis etiology may be explained as being secondary to an aplasia or hypoplasia of the vestibulocochlear nerve. The embryologic events involved in fetal growth between the 4th and the 8th weeks are crucial for bone growth, and may cause such disease. The labyrinth may be also involved, being aplastic or with a deformed or incomplete cavity. It is not uncommon to have a completely normal labyrinth,though[9].

Other study showed height and width of the middle portion of IAM ranged between 3 and $5 \mathrm{~mm}$ (mean $\pm S D, 4.04 \pm 0.639 \mathrm{~mm}$ ) and 3 and $5 \mathrm{~mm}$ $(3.96 \pm 0.692 \mathrm{~mm})$ respectively where in the present study on right side ranged between $(3.52 \pm 0.55 \mathrm{~mm})$ and $(3.37 \pm 0.63 \mathrm{~mm})$ almost similar with our values. The inferior and superior length of IAM ranged between 7 and $11 \mathrm{~mm}$ $(8.39 \pm 1.119 \mathrm{~mm})$ and 8 and $14 \mathrm{~mm}(10.75 \pm 1.655$ $\mathrm{mm}$ ) respectively even in our study it was ranging between 7 and $13 \mathrm{~mm}$. The average length of the posterior surface of petrous was $53.39 \pm 4.567 \mathrm{~mm}$ (range $45-60 \mathrm{~mm}$ ). The height and width of the fundus of IAM ranged between 2.5 and $4 \mathrm{~mm}(2.86 \pm 0.397 \mathrm{~mm})$ and 2 and $3 \mathrm{~mm}$ $(2.43 \pm 0.416 \mathrm{~mm})$ but in our study it was between 2 and $5 \mathrm{~mm}(3.26 \pm 0.503 \mathrm{~mm} \& 3.08 \pm 0.45 \mathrm{~mm})$ respectively. The width and height of the porus ranged between 3 and $7 \mathrm{~mm}(5.04 \pm 1.048)$, and 3 and $6 \mathrm{~mm}(4.11 \pm 0.631 \mathrm{~mm})$, respectively[1] in our study it was between 2 and $6 \mathrm{~mm}(3.86 \pm 0.70 \mathrm{~mm} \& 3.56 \pm 0.53 \mathrm{~mm})$ which was lesser than the previous studies.

One of the study described the anthropometry of IAM in addition to its 3D structure. They found the height and width of the middle portion of IAM 4.8mm (3.2-6.5mm) and 4.9mm (3.1-7mm), the height and width of the fundus of IAM $4.5 \mathrm{~mm}$ (3.7-5.6mm) and 4.6mm (3.3-5.7mm), and inferior length of IAM $9.6 \mathrm{~mm}(14.5-13.7 \mathrm{~mm})$ [8]. On comparing the observation of the presnt study it can be concluded that except mean superior and inferior length of IAM all other dimensions showed variations in the dimensions. The variations of dimensions may be attributed to the differences in race of the study population[10]. Thus the present study may provide best available dimensions of IAM in adult dry human skulls of South Indian Population. It may also help in evaluation of stenosis and congenital anomalies of IAM and important for head and neck surgeons in diagnosis of IAM pathologies.

\section{CONCLUSION}

The present study was done to obtain the measurements of different parameters of IAM among temporal bone of adult dry skulls using a casting method with PVS impression material. In the present study the mean height and width of IAM at porous end was $3.56 \& 3.86 \mathrm{~mm}$ on right side $\& 3.48 \& 4.13 \mathrm{~mm}$ on left side respectively. The mean height and width at middle of IAM was $3.52 \& 3.37 \mathrm{~mm}, 3.44 \& 3.47 \mathrm{~mm}$ on right and left side respectively. The mean height and width of IAM at Fundus end was $3.26 \mathrm{~mm}$ \& $3.08 \mathrm{~mm}$ on the right side and on left side was $3.36 \& 3.19 \mathrm{~mm}$ respectively. The Mean superior length \& inferior length on right side was $9.89 \& 8.43 \mathrm{~mm} \& 9.94 \& 8.59 \mathrm{~mm}$ respectively. The obtained was compared with the studies done by various authors showed that there is a differences in the obtained data among authors which emphasized on the fact that their will be racial and population differences, thus thursting on the fact to have thorough knowledge on the values of various parameters of IAM among different population as this is one common site of surgical importance with important cranial nerves emerging out of it.

\section{ACKNOWLEDGEMENTS}

We would like to acknowledge the help and support of other faculties and non-teaching staff members of the department. We would like to thank the ICMR for providing a forum for such research activities to be taken up by an individual. Thanks for the Ethical and scientific 
committee for their valuable support for the completion for this project.

\section{Conflicts of Interests: None}

\section{REFERENCES}

[1]. Farahani,Rr. M. Nooranipour, . \& Nikakhtar, K. V. Anthropometry of internal acoustic meatus. Int.J.Morphol.2007;25(4):861-865.

[2]. Prashaanthi. N, karpagamkrishnamoorthy. Morphometric Analysis of Internal Acoustic Meatus. Research J. Pharm. And Tech 2016;9(10):1575-1576.

[3]. Prashant E,Natekar, Fatima M DeSouza. Anatomical Landmarks: A surgical aid for identification of facial nerve to the internal acousticmeatus. 2001;17(3):117-119.

[4]. M. Fatih Erkoç et.al. Normative size evaluation of internal auditory canal with magnetic resonance imaging: review of 3786 patients. Folia Morphol.71(4):217-220.

[5]. Rajanigandha Vadagaonkar et. al. Morphometric analysis of IAM and its surgicall relevant relations in human temporal bones. Research journal of Pharmaceutical Biological and Chemical Sciences.2016;7(5):1584-1588.
[6]. A O El Sadik, M H Shaaban.The relationship between the dimension of IAC and the anomalies of the Vestibulocochlear nerve.Folia Morphol. 2017;76(2) :178-185.

[7]. Serigo Ricardo Marques. Morphometric Analysis of IAC by CT Imaging. Iran Radiol.2012; Jun;9 (2):7178.

[8]. M. V.Kirtane.The internal Auditory Canal .Indian Journal of Otolaryngology.December 1977;29(4):155-157.

[9]. Ivair Massetto Junior. Internal auditory meatus stenosis - case report. Rev. Bras. Otorrinolaringol 2008;74(2).

[10]. Sakashita, T. \& Sando, I. Postnatal development of internal auditory canal studied by computer aided three dimensional reconstruction and measurements. Ann. Otol. Rhinol. Laryngol., 1995;104(6):46975.

How to cite this article:

Mamatha Y, Trisha.K.R, Vishal Kumar. ANTHROPOMETRY OF INTERNAL ACOUSTIC MEATUS IN DRY ADULT HUMAN SKULL USING CASTING METHOD. Int J Anat Res 2019;7(1.1):6113-6118. DOI: $10.16965 /$ ijar.2018.417 